\title{
DISCURSO DE SAUDAÇÃO À PROFESSORA IVETTE SENISE FERREIRA POR OCASIÃO DE SUA POSSE COMO DIRETORA DA FACULDADE DE DIREITO USP
}

\author{
Celso Lafer \\ Professor Titular do Departamento de Filosofia e \\ Teoria Geral do Direito da Faculdade de Direito \\ da Universidade de São Paulo
}

\begin{abstract}
É uma alegria e uma satisfação, como colega, amigo e admirador, saudar Vossa Excelência professora Ivette Senise Ferreira - em nome da Congregação, por ocasião de sua posse como Diretora da nossa Faculdade. A solidez e a seriedade da trajetória acadêmica de V Excia. são de todos conhecidas. Trata-se de uma trajetória que, na sua etapa inicial, associa os cursos de graduação, especialização e pós-graduação na nossa Faculdade a cursos de especialização e pósgraduação na Universidade de Paris; que se caracteriza por uma dedicada atividade didática da qual se vêm beneficiando ao longo dos anos os nossos alunos; por uma ativa participação em bancas examinadoras na USP e em outras instituições; pela sólida orientação a alunos de mestrado e doutorado; por uma relevante e responsável participação em colegiados e em comissões dentro e fora da USP que deram a V Excia. uma experiência administrativa que será de grande valia no exercício de suas novas funções; pela diversificada e rica participação em entidades, congressos, seminários, mesas-redondas e simpósios, indicativa não apenas de uma sensibilidade acadêmica em relação a temas e problemas da agenda do nosso país e do mundo, mas também da importância do entrosamento do intelectual com as instâncias da sociedade civil.
\end{abstract}

As cadências da carreira de V Excia., que obedeceram aos ritmos de quem estudou, casou, lecionou, advogou, criou quatro filhas e cuidou da organização da casa, proporcionaram-me o privilégio de tê-la como aluna no curso de pósgraduação. Lembro-me perfeitamente, até hoje, passados tantos anos, da sua excepcional exposição sobre o De Monarquia de Dante, que era um dos textos de seminário, exemplificativo do argumento da unidade nas formas de conceber a organização da ordem internacional. Esta condição, de seu professor na pósgraduação, deu-me a oportunidade de participar, em 1982, da sua banca de 
doutoramento. A tese de V. Excia., sobre o aborto legal era, como disse na ocasião, uma excelente tese, muito bem redigida, argumentada e documentada, que tinha a coragem de tratar de um tema difícil e polêmico. Com efeito, o aborto inevitavelmente gera a controvérsias, pois toca de perto "one's philosophy, one's experiences, one's exposure to the raw edges of human existence, one's religious training, one's attitudes towards life and family and their values"- nas palavras do "Justice Blackmun, da Suprema Corte dos EUA, que relatou o caso Roe $x$ Wade que $\mathrm{V}$ Excia. comentou e discutiu na sua tese. Não escapou igualmente à sua tese uma relevante percepção: no caso do aborto, a repressão penal tem sido impotente, porque existe, na precisa formulação de V. Excia., "uma certa tolerância do meio social que implícita ou explicitamente atribui à mulher" nos casos de aborto, "a justificativa de um estado de necessidade supralegal, por diferentes fundamentos, conforme as circunstâncias"

Esta rápida referência à sua tese de doutorado é um bom ponto-departida para uma reflexão sobre o seu percurso, que, penso eu, tem muito a ver tanto com o seu campo acadêmico $O$ Direito Penal - quanto com o olhar que guiou a escolha dos temas que $\mathrm{V}$ Excia. versou.

O Direito Penal desempenha a clássica função de controle social, conservando e preservando uma sociedade por meio da proibição a condutas tidas como socialmente indesejáveis e valendo-se da sanção para salvaguardar as leis penais da erosão de ações que a elas se contrapõem. O Direito Penal porque proíbe e reprime, em função da herança do "iluminismo" voltado para conter o arbítrio do poder, é especialmente cuidadoso na tipificação das condutas ilícitas, na análise da responsabilidade, no estudo do bem jurídico tutelado por suas normas. Por isso mesmo a teoria do Direito Penal na vigência do estado de direito instiga o rigor e a disciplina dos conceitos.

O rigor e a disciplina dos conceitos permeiam os trabalhos acadêmicos de V Excia., professora Ivette Senise Ferreira, e seguramente foi esta propensão ao rigor e à disciplina que the permitiu levar adiante sua carreira profissional e ao mesmo tempo lidar com as múltiplas solicitações que a vida usualmente impõe à condição feminina. Não é de fácil equacionamento, no dia a dia, esta multiplicidade de solicitações. Um relato admirável dos dilemas provocados por estas solicitações se encontra no livro que reúne a correspondência entre Hannah Arendt e Mary McCarthy. Nesta correspondência, que se estende de 1949 a 1975, duas grandes amigas que foram intelectuais de primeira plana tratam do seu cotidiano - um 
cotidiano no qual os grandes projetos intelectuais de ambas e as discussões políticas se mesclam com os cuidados da casa, a conversa mais livre sobre as pessoas; as críticas e as maledicências de que foram alvo; as alegrias e os dramas do amor; a educação de filho; a família; as roupas; o cabeleireiro; a saúde e a doença. Em síntese, trata-se de um livro que é um registro muito concreto a respeito da condição feminina tal como vivida por duas intelectuais que se destacaram e que conseguiram lidar e bem com a acima referida multiplicidade de solicitações. "They kept their powder dry" e afirmaram a sua identidade, da mesma maneira que V. Excia. Profa. Ivette - afirmou a sua.

Encaminho-me agora na análise de sua trajetória, aos seus temas de estudo, permitindo-me antes fazer uma pequena digressão pessoal. Quando aluno da Faculdade, no início dos anos 60, passei igualmente pelo curso de Letras da Faculdade de Filosofia e tive a oportunidade de conhecer de perto, graças ao prof. Antonio Candido, do qual fui aluno, sua mulher D. Gilda de Mello e Souza professora de estética da Faculdade de Filosofia. Na época, li a tese de doutorado de D. Gilda, A moda no século XIX, hoje acessível com o título $O$ espírito das roupas, em bela edição da Cia. das Letras, e fiquei impressionado com a originalidade de um olhar que desvendou chaves do funcionamento da sociedade através de um assunto aparentemente pouco acadêmico. Também me impressionou o que D. Gilda, naquela época, escreveu sobre o universo feminino e a vocação da minúcia e o apego ao concreto, tal como impactava o texto do romance $A$ maçã no escuro, de Clarice Lispector. Seguindo a bibliografia de D. Gilda, acabei por ler as sutis análises de Simmel sobre a cultura feminina, o livro de Viola Klein sobre o conteúdo ideológico do assim chamado caracter feminino e muito especialmente $A$ room of one's own, de Virginia Woolf. Virginia Woolf discutia, no final dos anos 20, a importância para uma mulher escritora ter um espaço próprio ("a room of one's own") e recursos próprios para superar as limitações à sua criatividade impostas pela falta de recursos materiais, de escolaridade apropriada, de experiência social e de acesso aos meios de comunicação. A leitura de Virginia Woolf me marcou e me convenceu, pois neste livro, assim como em Three Guineas, que é da década de 30, ela sublinha que homens e mulheres podem olhar para as mesmas coisas mas vê-las de maneira diferente. $O$ reconhecimento do alcance da diferença, lastreada no gênero, sobretudo na medida em que, na época, as mulheres eram no espaço público "social outsiders" me fez lembrar a avaliação epistemológica de Ortega y Gasset, para quem, à luz da razão vital, a perspectiva não-distorce mas sim organiza a realidade. 
A multiplicidade das perspectivas, diria eu, como bom liberal de inspiração pluralista, enriquece a nossa percepção da realidade que é ontologicamente complexa. Nesta multiplicidade de perspectivas, inequivocamente a perspectiva feminina é não-só eticamente devida e socialmente indispensável, como intelectualmente heurística. Neste sentido, como dedicado aluno de Hannah Arendt, lembro que ela, ao se afastar do clássico tema da morte, tido como masculino, deslocou o ângulo da filosofia política ao afirmar, em The Human Candition, que o princípio ontológico da ação política é a natalidade e a esperança do novo, inerentes ao potencial de cada novo ser humano.

Esta digressão, profa. Ivette Senise Ferreira, tem como objetivo encaminhar o meu argumento sobre os assuntos que $\mathrm{V}$ Excia. estudou. Penso que a sua obra se caracteriza por uma discussão de "temas novos" para os quais, na escolha, deve ter contribuído o olhar da condição feminina que permitiu à $\mathrm{V}$ Excia. ver com clareza concreta a importância do novo e do relevante no seu campo de estudos. A sua tese de titular de 1993 sobre a tutela penal do patrimônio cultural como expressão do campo de abrangência da proteção jurídica ambiental; os seus estudos sobre o Direito Penal Ambiental; as suas investigações sobre os crimes da informática; a sua análise sobre a intimidade e o Direito Penal; as suas reflexões sobre penas alternativas e substitutivos penais para dar alguns exemplos - são indicativos da sua sensibilidade a "temas novos", temas que V. Excia. discute com o rigor e a disciplina dos conceitos hauridos nos cuidados inerentes à convivência com a melhor teoria do Direito Penal.

Por isso, creio que V. Excia. - profa. Ivette está particularmente talhada para dirigir a nossa Faculdade, - seu espaço próprio desde os tempos de estudante - neste momento, na antevéspera do milênio. Com efeito, o que precisa a nossa Faculdade é, ao mesmo tempo, de uma indispensável abertura aos "novos temas". impostos pela agenda contemporânea e, no trato destes temas, um rigor de conceitos, e uma disciplina acadêmica para professores e alunos . indispensáveis à excelência no campo jurídico e à manutenção e ampliação da qualidade da USP e da nossa muito querida e tradicional "velha e sempre nova Academia" V Excia. seguramente imprimirá esta "vis directiva" à sua gestão, pois ela está em consonância com o percurso de sua vida de professora e estudiosa e com a sua ininterrupta vivência do dia a dia da nossa Faculdade e de seus problemas.

$\mathrm{V}$ Excia., profa. Ivette, será a primeira mulher a dirigir a nossa Faculdade, como será também a primeira mulher a dirigir uma das Faculdades 
tradicionais da USP - estou pensando na Politécnica e na Faculdade de Medicina e igualmente na própria Faculdade e Filosofia que foi o núcleo organizador da USP, na inovadora concepção de seus fundadores na década de 30. Qual é o significado deste evento que, com razão, tem sido destacado para a opinião pública pelos meios de comunicação?

Bobbio, na análise do conceito de revolução, destaca que ele contém dois elementos: o do evento dramático fundador por exemplo a Revolução Francesa, a Revolução Russa e o da mudança significativa trazida pelo evento qualificado como revolucionário. Nem sempre, diria eu como reformista, a mudança radical é precedida de um movimento revolucionário. É o caso, como lembra Bobbio, da Revolução Industrial ou, acrescento eu, da Revolução da Informática cuja conseqüência no âmbito penal V. Excia. examinou em seus estudos. É igualmente, como lembra Bobbio, o caso da Revolução Feminina que foi aluvionalmente provocando uma mudança radical nos costumes e na dinâmica de funcionamento da sociedade civil. Para a aceleração deste processo sem dúvida contribuiu, como diria o presidente Fernando Henrique Cardoso, na sua análise da teoria da mudança, o "curto-circuito" da inspiração libertária de maio de 1968 que nós, profa. Ivette, acompanhamos já como adultos.

São etapas deste processo de mudança e mentalidade, na nossa Faculdade, o bem-sucedido concurso de livre-docência da professora Esther de Figueiredo Ferraz que honra a nossa Casa como advogada, jurista, educadora e primeira mulher ministra de Estado em nosso país e, posteriormente, o concurso, para titular da professora Nair Lemos Gonçalves que foi, de 1978 a 1982, a primeira mulher a ocupar a posição de vice-diretora de nossa Faculdade.

Como disse V Excia., profa. Ivette, numa de suas entrevistas à imprensa, por ocasião da sua indicação, refletindo sobre este processo: "O preconceito é coisa do passado, e permanece mais na cabeça daquelas pessoas mais idosas e conservadoras, que estão sendo substituidas por essa nova maneira de ver o ambiente juridico - professores e magistrados mais jovens - que foram criados num outro sistema" (Gazeta Mercantil 6/julho/1998 p. 4). A professora Odete Medauar, como vice-diretora da gestão do prof. Álvaro Villaça que ora deixa a direção da Faculdade, com os nossos melhores agradecimentos pelo que pôde realizar e a profa. Ada Pellegrini Grinover, dinâmica e atuante pró-reitora de graduação da nova gestão do Magnífico Reitor, prof. Jacques Marcovitch, são 
exemplos do reconhecimento axiológico de nova mentalidade apontada por $\mathrm{V}$. Excia. em matéria e gênero e profissão.

Como estudioso e também como defensor dos direitos humanos, hoje com a responsabilidade, como embaixador do Brasil em Genebra de também representar o país na Comissão de Direitos Humanos da ONU, sei que existe uma defasagem entre o reconhecimento histórico da hierarquia axiológica de um valor e a sua plena realizabilidade.

A igualdade em geral e a igualdade entre os sexos requerem a tolerância, e o tolerar e o ser tolerado, como dados básicos da convivência coletiva pluralista, têm tudo a ver, na relação governantes-governados, com a ação de uma cidadania democrática e com a asserção no espaço da palavra e da ação, do "direito a ter direitos" para novamente recorrer à formulação de Hannah Arendt. A "tolerance" como atitude, assume muitas formas e a "toleration", como prática, pode ser organizada de diferentes maneiras, sublinha Michael Walzer em livro recente sobre a matéria. É por este motivo que, refletindo sobre a nossa era como uma "era dos direitos" Bobbio aponta que o processo de afirmação do "direito a ter direitos' passa por fases: a da positivação jurídica em Declarações; a da generalização, e da internacionalização e a da especificação. A especificação "consiste na passagem gradual, porém cada vez mais acentuada, para uma ulterior determinação dos sujeitos titulares de direitos" Foi assim que se passou da idéia abstrata de liberdade para as liberdades singulares e concretas - de consciência, de opinião, de imprensa, de reunião, etc num movimento que $\mathrm{V}$ Excia. registra ao estudar como o direito à intimidade resulta do desdobramento de outros direitos como a inviolabilidade do domicílio, da correspondência e dos segredos.

Os direitos da mulher estão hoje, inequivocamente, na etapa da especificação. Este processo se detecta bem no plano do Direito Internacional, numa evolução que começa para exemplificar -, com a criação, em 1946, através de resolução do Conselho Econômico e Social da ONU, da Comissão sobre o status da mulher; da Convenção de 1952, sobre os direitos políticos da mulher; da Convenção de 1979, sobre a eliminação de todas as formas de discriminação contra a mulher; da resolução da Assembléia Geral de 1958, sobre a implementação da "Nairobi Forward-looking strategies for the advancement of women"; da resolução de 1988, do Conselho Econômico e Social que estabeleceu um sistema de relatoria para monitorar, rever e avaliar a implementação das acima mencionadas estratégias de Nairobi; pela inclusão na agenda internacional do tema da mulher como parte dos 

por ocasião de sua posse como Diretora da Faculdade de Direito da USP

"temas globais" da década de 90, na Conferência de Pequim da ONU de 1995, da qual V. Excia. participou como presidente da Associação Brasileira de Mulheres de Negócios e Profissionais.

O eixo da Conferência de Pequim foi Ação para a Igualdade, o Desenvolvimento e a Paz. Teve como antecedente próximo a Conferência de Viena, de 1993, da ONU sobre direitos humanos, cuja Declaração e Programa de Ação representam um paradigma da fase de especificação do "direito a ter direitos" Em Viena a comunidade internacional, com o respaldo da sociedade civil que se articulou através de organizações não-governamentais, afirmou que os direitos das mulheres são parte integrante indivisível dos direitos humanos universais. Especificou que a plena participação das mulheres, em condições de igualdade na vida política, civil, econômica e social e cultural, em todos os níveis, é um dos objetivos prioritários da comunidade internacional. Destacou igualmente as características próprias da violência contra a mulher tema cuja importância $V$ Excia. sabe avaliar como penalista e mulher. Viena assinalou também a importância da integração e da plena participação das mulheres como agentes e beneficiárias do processo de desenvolvimento, reiterando o vínculo com o conceito de desenvolvimento sustentável consagrado na Rio-92, seja na sua Declaração seja no capítulo 24 da Agenda 21 - vínculo que para V. Excia. é muito claro à luz dos seus estudos sobre Direito Ambiental e da sua condição de mulher.

Permiti-me fazer estas considerações - profa. Ivette, meus caros colegas e alunos para explicitar o alcance da solenidade de hoje, na véspera do aniversário da fundação dos cursos jurídicos, em 11 de agosto de 1827, que assinala o ińício da trajetória da nossa Faculdade na vida do Brasil. Com efeito, a posse de $\mathrm{V}$ Excia. como Diretora, por tudo aquilo que a nossa Casa representa no cenário nacional, é uma forte e concreta expressão deste processo de especificação, que é inerente à asserção do "direito a ter direitos"

Concluo assim esta saudação à V Excia., profa. Ivette, na certeza que pelas suas qualidades pessoais; pela sua comprovada capacidade de lidar com a "multiplicidade de solicitações" inerente à sua experiência de vida como mulher; pela sua abertura aos temas novos abordados com o rigor e a disciplina jurídica dos conceitos; pela representatividade que a sua posse assume no processo de especificação dos direitos da mulher; que a sua gestão se inaugura sob os melhores auspícios. Estamos em boas mãos. Felicidades e sucesso é, sinceramente, o que 
desejam a V Excia. os seus colegas e alunos e muito afetuosamente este seu amigo e admirador.

São Paulo, 10 de agosto de 1998. 